\title{
Comparison of executive and visuospatial memory function in Huntington's disease and dementia of Alzheimer type matched for degree of dementia
}

\author{
K W Lange, B J Sahakian, N P Quinn, C D Marsden, T W Robbins
}

\begin{abstract}
Groups of patients with Huntington's disease and probable dementia of Alzheimer type (DAT) matched for level of dementia on the basis of mini mental state examination scores were compared in several tests of visual memory and tests sensitive to frontal lobe dysfunction. Whereas recall of patients with DAT tended to be worse on the Kendrick object learning test, the two groups were equivalent on tests of sensorimotor ability and delayed matching to sample performance. By contrast, the patients with Huntington's disease were significantly worse on tests of pattern and spatial recognition, simultaneous matching to sample, visuospatial paired associates, and on three tests sensitive to frontal lobe dysfunction-namely, the Tower of London test of planning, spatial working memory, and a visual discrimination learning and reversal paradigm. The impairments in these tests, however, did not always qualitatively resemble those seen in patients with frontal lobe damage and may be more characteristic of primary neostriatal deficit. In the visual discrimination paradigm the patients with Huntington's disease were significantly worse than the patients with DAT at the simple reversal stage, where they displayed significant perseveration to the previously rewarded alternative. The results are consistent with the hypothesis that patients with Huntington's disease exhibit deficits in tests sensitive to frontostriatal dysfunction and that this form of intellectual deterioration is qualitatively distinct from that seen in Alzheimer's disease.
\end{abstract}

\section{(F Neurol Neurosurg Psychiatry 1995;58:598-606)}

Keywords: Huntington's disease; Alzheimer's disease; cognition

There is currently much interest in whether dementias arising from different causative factors exhibit qualitatively different patterns of cognitive deficit. This is an issue of some importance, not only in practical terms, but also for understanding the underlying neural substrates of the disorders and the specificity of cognitive deficits over and above generalised intellectual deterioration due to dementia. Previously, Albert et $a l^{1}$ and Cummings and Benson $^{2}$ have proposed a distinction between dementia associated with primary subcortical neuropathology (for example, basal ganglia disorders such as Parkinson's and Huntington's diseases) and dementia in which the primary neuropathology is in the association neocortex (for example, dementia of Alzheimer type (DAT)). This distinction between "subcortical" and "cortical" dementia has proved somewhat controversial, not least because clinical rating scales have sometimes failed to support it, but also because the nature of some of the cognitive deficits seen in subcortical dementia may be reminiscent of the symptoms of frontal lobe damage. These are often referred to as examples of executive dysfunction, because they present as problems of planning, attentional set shifting, and slowness of response, rather than the typical signs of posterior cortical damage which lead to such symptoms as aphasia, agnosia, and global amnesia. It seems likely that striatal dysfunction, as occurs in Parkinson's disease and Huntington's disease, would lead to similar executive deficits because of the existence of several corticostriatal loops that highlight the functional inter-relationships between different parts of the frontal cortex and the basal ganglia. ${ }^{3}$ Of particular significance for Huntington's disease in view of the primary site of its striatal neuropathology may be the anatomical and functional relations that exist between the caudate nucleus and the prefrontal cortex. ${ }^{3}$ Despite these neurobiological considerations and evidence that impairment of daily functioning in patients with early Huntington's disease more likely results from deficits in executive function than motor disability, ${ }^{4}$ there has been relatively little analysis of executive dysfunction in Huntington's disease. ${ }^{5}$

Explicit comparisons among these different forms of dementia have also been lacking ${ }^{6}$ although there have been several recent comparisons of Huntington's disease and DAT on different forms of memory. Hodges et $a l^{7}$ compared a group of patients with DAT and a group with Huntington's disease, matched for overall level of dementia, on a battery of tests of semantic and episodic memory. Whereas the patients with DAT were significantly more impaired on measures of delayed verbal and figural episodic memory, patients with 
Huntington's disease did worse on letter fluency, often associated with frontal lobe damage. There have been few comparisons between patients with Huntington's disease and DAT on tests of executive function, ${ }^{5}$ although there is growing evidence for differences between DAT and Parkinson's disease in this regard. For example, Litvan et $a l^{8}$ showed that demented patients with Parkinson's disease perform substantially worse than patients with DAT on tests of executive function, such as the ability to perform the Wisconsin card sorting test (WCST), whereas semantic and episodic memory were significantly worse in the patients with DAT.

We have found that patients with Parkinson's disease who are early in the course of the disease and yet to take medication are significantly worse than patients early in the course of DAT in tests of visual discrimination learning and attentional set shifting analogous to the WCST..$^{10}$ As we have also shown that the attentional set shifting test is sensitive to damage to the frontal cortex, ${ }^{11}$ we have hypothesised that patients with Parkinson's disease may be especially prone to frontal type deficits early in the course of the disease. ${ }^{12}$ Whereas patients with DAT can also be expected to be impaired in tests of executive function as the disease progresses, both neuroimaging and neuropsychological evidence supports the hypothesis that anterior cortical functions are relatively more immune to disruption. ${ }^{13}$ For example, a recent study showed that whereas patients with DAT can be severely impaired on a test of spatial working memory that is sensitive to frontal lobe dysfunction, they do not necessarily fail because of the impaired strategy that has been shown to account for much of the frontal deficit. ${ }^{14}$

Consequently, the main aim of this study was to compare patients with Huntington's disease and DAT matched for level of dementia on tests of executive function that we have previously shown to be selectively sensitive not only to frontal lobe damage ${ }^{115}$ but also to basal ganglia disorders other than Huntington's disease, such as Parkinson's disease, progressive supranuclear palsy, and multiple system atrophy. ${ }^{16} 17$ The first hypothesis to be tested was thus that such tests of executive function may be more sensitive to cognitive deficits in Huntington's disease than DAT. Whereas patients with basal ganglia disorder do exhibit selective impairments on these tests, previous evidence has indicated that the precise nature of the deficits may differ qualitatively compared with those seen after frontal lobe lesions, perhaps reflecting the different contributions of the striatal and cortical components of the common neuroanatomical circuitry, termed corticostriatal loops.1217 Thus a secondary hypothesis was that the nature of any executive deficits seen in the Huntington's disease group might be different from those found after frontal lobe damage.

There were several aspects of the study requiring careful control. Firstly, to assess the selectivity of the executive deficits in Huntington's disease, we used several tests from the Cambridge neuropsychological test automated battery (CANTAB) that have explicitly been used to assess visuospatial learning and memory in Alzheimer's disease, ${ }^{18}$ some of which have been shown to be more sensitive to temporal rather than frontal lobe damage. ${ }^{19}$ Assessment of visual memory and learning in Huntington's disease has also not previously received much attention. ${ }^{5}$ Secondly, it was important to match for the degree of clinical dementia so that any differences in specific cognitive functions could not be attributed to non-specific intellectual deterioration. For the purposes of matching we used a validated measure of global dementia, the mini mental state examination (MMSE) ${ }^{20}$ Another screening instrument for dementia, Kendrick's object learning test (taken from the Kendrick cognitive tests for the elderly) ${ }^{21}$ was also used and it was possible to match patients according to a premorbid index of IQ. ${ }^{22}$ To gauge the absolute levels of impairment in the Huntington's disease and DAT groups we have also provided data for separate large groups of normal controls matched as far as possible for age and premorbid estimates of verbal IQ to the DAT and Huntington's disease groups. As might be expected from the recent standardisation ${ }^{23}$ of much of the CANTAB battery, the performance of the younger control group was slightly superior to that of the older group on certain tests. Whereas this might affect the relative degree of age related impairment between the Huntington's disease and DAT groups, it could not account for any inferior levels of executive performance in the Huntington's disease group in the hypothesis under test. Therefore, for the purposes of this study we focused on a direct comparison of the performance of the two patient groups.

\section{Methods}

SUBJECTS

Consecutively presenting patients with Huntington's disease or mild or moderate probable DAT were assessed. In all, 17 patients with probable DAT and 13 with Huntington's disease were tested. Complete data were only obtained on $13(83 \%)$ patients with DAT and $10(77 \%)$ patients with Huntington's disease, because of fatigue and lack of comprehension of the instructions on some tests. As most patients with DAT were primarily in the early stages of the disease with mainly mild symptoms, it was feasible to match the two groups for level of dementia, as assessed with a clinical rating scale (see later).

Patients with dementia of the Alzheimer's type All thirteen patients attended the Maudsley Hospital and all were seen on an outpatient basis through the memory clinic. ${ }^{24}$ Patients were assessed and diagnosed by a consultant psychiatrist in concordance with a second psychiatrist as having DAT following criteria outlined for "probable Alzheimer's disease" 
Table 1 Clinical characteristics of patient group

\begin{tabular}{|c|c|c|c|c|c|c|c|}
\hline & No & Age & $\begin{array}{l}\text { Sex } \\
M: F\end{array}$ & $\begin{array}{l}\text { Disease } \\
\text { duration }\end{array}$ & $N A R T$ & $K O L T$ & $M M S E$ \\
\hline $\begin{array}{l}\text { HD } \\
\text { DAT } \\
t(21)\end{array}$ & $\begin{array}{l}10 \\
13\end{array}$ & $\begin{array}{c}51 \cdot 5(3 \cdot 3) \\
69 \cdot 2(2 \cdot 0) \\
4 \cdot 81^{\star \star}\end{array}$ & $\begin{array}{l}3: 7 \\
9: 4\end{array}$ & $\begin{array}{l}7.4(0.9) \\
3.67(0.33)\end{array}$ & $\begin{array}{c}106 \cdot 6(4 \cdot 9) \\
111(2 \cdot 1) \\
0.98\end{array}$ & $\begin{array}{c}18.4(2.4) \\
13.0(1.5) \\
2.00\end{array}$ & $\begin{array}{c}20.3(1.4) \\
19.2(1.6) \\
0.53\end{array}$ \\
\hline
\end{tabular}

$\star \star \mathrm{P}<0.01$.

Data shown are mean $(S E M)$ values; NART $=$ National adult reading test ${ }^{22}$; KOLT $=$ Kendrick object learning test ${ }^{21} ;$ MMSE $=$ mini mental state examination ${ }^{20} ; \mathrm{HD}=$ Huntington's disease; DAT $=$ dementia of Alzheimer type. tive degree of age related impairment, control data for the main dependent variables have been provided from a large group of healthy normal control subjects (table 2). These were drawn from a large population of volunteers aged between 55 and 69 years from London, Cambridge, and Newcastle-upon-Tyne (North-East Age Research Panel) in the recently published standardisation of many of the tests of the CANTAB battery. The controls had no history of neurological or psychiatric disorder.

by McKhann et al..$^{25}$ All patients were considered to be in the mild and moderate stages of the disease, with eight patients in stage 1 and five patients in stage 2 of the clinical dementia rating (CDR) scale, in which CDR stage 1 is mild, CDR stage 2 is moderate, and CDR stage 3 is severe dementia, as defined by Hughes et $a .^{26}$ To determine the diagnosis, patients were first seen by a psychiatrist on attending the memory clinic, where they received a semistructured clinical interview and a physical examination. ${ }^{27}$ After the physical examination, which included the testing of visual acuity with Snellen cards, blood was taken for laboratory investigations. Unenhanced CT was then performed with the Maudsley Hospital GE 9800 scanner to determine the extent of brain atrophy, and exclude other forms of dementia, especially multiinfarct dementia. The patients (nine men and four women) included in the study were then seen on a subsequent visit by a clinical psychologist for detailed neuropsychological assessment, including the tests described in more detail later. Table 1 gives further details of the 13 patients.

\section{Patients with Huntington's disease}

Ten patients with Huntington's disease were included in the study. The diagnosis was based on personality or intellectual change, together with the presence of chorea or the typical impairment of voluntary movement. These symptoms were not present at birth, were insidious in onset, had gradually become worse, and were associated with a definite family history of at least one other member with these characteristic neurological symptoms and signs. At the time of investigation, the severity of the hyperkinetic involuntary movements was rated according to the chorea scale of the quantified neurological examination, on a scale ranging from 0 to 25 points ${ }^{28}$; this patient group scored a mean of 14.8 (SEM 1·1). None of the patients had significantly impaired visual acuity or hearing. At the time of the study, the patients did not exhibit acute confusion or acute psychosis and were not receiving any medication known to affect the CNS. Informed consent was obtained from all patients participating in the study.

\section{Controls}

The main purpose of the study was explicitly to compare patients with Huntington's disease and those with DAT. To gauge the rela-

\section{MATERIALS AND PROCEDURES}

The main testing procedures were taken from the Cambridge neuropsychological test automated battery (CANTAB), a series of computerised paradigms run on an Acorn BBC Master microcomputer with a high resolution Microvitec colour monitor and a Microvitec (Touchtech 501) touch sensitive screen. The general rationale and utility of the battery for clinical investigations has recently been explained in some detail. ${ }^{29}$ Subjects were seated roughly $0.5 \mathrm{~m}$ from the monitor and it was explained that they would have to respond to stimuli by touching the screen. They were introduced to the apparatus by way of a sensorimotor screening task in which they were asked to respond to a series of flashing crosses on the screen by placing the index finger of their preferred hand on the centre point of each cross. The finger had to be held in place for six seconds at which time another cross appeared. After a short demonstration series in which three consecutive crosses were touched, subjects were presented with a series of 10 crosses to touch at six second intervals. Measures were taken of the latency to point (to the nearest $0.01 \mathrm{~s}$ ) and the accuracy of the initial pointing contact with the screen (computed in terms of vectorial displacement from the centre of the cross in arbitrary units based on $\mathrm{X}-\mathrm{Y}$ co-ordinates). No subjects were excluded on the basis of their deficient performance on this task.

\section{Tests of visual memory and learning}

In the first part of the test session, all patients received computerised tests of visual memory and learning identical to those previously described in detail. ${ }^{18}$ These included tests of pattern and spatial recognition, simultaneous and delayed matching to sample, and a conditional visuospatial associative learning task. In the pattern recognition task, abstract visual stimuli are displayed one by one in the centre of the screen before recognition memory is tested in a two alternative forced choice task, where the original stimulus is presented with a novel one and the subject has to pick the original. The test consists of two lists of 12 stimuli each, comprising 24 in all. In the spatial recognition task, open white squares are presented in a number of spatial locations on the screen, before recognition memory for location is tested, again with a two alternative forced choice procedure. There were four blocks of five stimuli each, comprising 20 in all. In the matching to sample test, the first 
phase (perceptual matching) consists of the simultaneous presentation of a complex abstract stimulus, varying in both colour and shape, with four matching stimuli. Subjects are required to choose the matching stimulus in a four alternative forced choice procedure. In the second phase (memory matching), the matching stimuli are presented in five trial blocks after a delay of $0,4,8$, or 16 seconds, followed finally by a retest at zero seconds. This delayed matching to sample test thus assesses the forgetting of the stimuli to be recognised after a short delay.

The conditional visuospatial paired associates test is identical to one described as the delayed response task in Sahakian et al. ${ }^{18}$ Here, however, the emphasis was on the learning as distinct from mnemonic aspects of the task. Abstract visual stimuli were presented one by one in a ring of six (and in the last stage, eight) boxes arranged around the screen. The stimuli were then re-presented one by one in the centre of the screen and the subject indicated in which box they had been previously presented. Subjects were given up to 10 trials to learn the location of each stimulus of the set before proceeding to the next stage. Failure to reach criterion at any stage resulted in the premature termination of the test. The test began with only one stimulus location to be remembered and then gradually increased to two, three, six, and eight stimuli.

\section{Tests of planning and spatial working memory}

Spatial short term memory task-In this computerised Corsi block tapping task, ${ }^{30}$ spatial short term memory capacity was determined from the ability of subjects to remember a sequence of squares on the screen, as described in detail in an earlier publication. ${ }^{15}$ Spatial short term memory span was calculated as the highest level at which the subject successfully recalled at least one sequence of boxes.

Spatial working memory task ${ }^{15}$-In this task the subject was required to search through spatial arrays of boxes to find tokens. Importantly, once a blue token had been found within a particular box, then that box would never be used to hide another token. On each trial, the total number of blue tokens to be found corresponded to the number of boxes on the screen as every box was used just once.

Errors were scored according to the number of occasions on which a subject returned to open a box in which a blue counter had already been found. After four practice trials with three boxes, there were four test trials with each of four, six, and finally eight, boxes. The patient groups were compared in terms of the total number of errors summed across the 12 test trials.

Planning task-This is a modification of the Tower of London task ${ }^{31}$ in which the subject has to move coloured "balls" on the screen from an initial arrangement to one corresponding to the goal arrangement shown in the top half of the screen, as described in detail previously. ${ }^{15}$

The starting position of the balls was varied such that in any particular trial the solution could only be reached after a minimum of two, three, four, or five moves. Subjects were instructed to examine the position of the balls at the beginning of each problem and attempt to solve it in the minimum possible number of moves. This was both given to them verbally and displayed on the screen throughout each trial. They were encouraged not to make the first move until they were confident that they could execute the entire sequence needed to solve the problem. The maximum moves allowed corresponded to twice the minimum number possible plus one, or plus two in the case of "five move" problems. The latency measures for thinking time previously employed to assess neurosurgical cases ${ }^{15}$ and patients with basal ganglia disorders ${ }^{12}$ are not reported in detail here.

Visual discrimination/attentional set shifting paradigm - The computerised visual discrimination/attentional set shifting paradigm has been described in detail elsewhere. ${ }^{9}$ Briefly, subjects are trained on a series of visual discriminations that vary in two perceptual dimensions, one of which is relevant and one of which is irrelevant, on the basis of feedback provided automatically by the computer. At critical points subjects are required first to maintain attention to different examplars within the same dimension (intradimensional shift) and then to shift attention to the previously irrelevant dimension (extradimensional shift). The other stages are defined and explained in previous papers ${ }^{9}$ and in the results section. For each stage, continuation to the next one was dependent on a criterion of six successive correct responses being reached. If criterion was not reached at the 50th trial of a stage, then the test was discontinued and subjects did not proceed to the next stage. More detailed explanation and rationales for the exact design of the test can be found in previously published articles. ${ }^{91032}$

\section{STATISTICAL ANALYSIS}

For most of the dependent variables, analysis of variance (ANOVA) ${ }^{33}$ was used to compare the Huntington's disease and DAT groups. Data were transformed where appropriate (when there was a positive skew on latency variables). For most of the test variables, the ANOVA model was a two factor design that included a between subjects factor (group) and a within subject factor (for example, difficulty level). Student's $t$ tests were applied to test the significance of differences between means where factorial ANOVA was not required.

For the attentional set shifting task, the data for the numbers of subjects passing or failing each stage of the test were cast into contingency tables and analysed by the likelihood ratio method. ${ }^{34} 35$ This method is particularly useful (a) for analysing data with small cell frequencies, as occurs in some of the data to be presented, and (b) for partitioning inhomogeneities in the contingency table by additive, orthogonal contrasts. The resulting "information" statistic (2i) is distributed as $\chi^{2}$. 
Table 2 Means (SEM) for the normal control samples

\begin{tabular}{lcc}
\hline & For Huntington's disease group & For DAT group \\
\hline & Working memory and planning battery & $(\mathrm{n}=222)$ \\
& $(\mathrm{n}=55)$ & $67 \cdot 3(0 \cdot 1)$ \\
Age (y) & $55 \cdot 6(0 \cdot 6)$ & $117 \cdot 9(0 \cdot 4)$ \\
NART & $116 \cdot 5(1 \cdot 0)$ & $5 \cdot 0(0 \cdot 1)$ \\
Spatial span & $5 \cdot 3(0 \cdot 1)$ & \\
Spatial working memory & $39 \cdot 6(3 \cdot 2)$ & $46 \cdot 1(0 \cdot 9)$ \\
$\quad$ (Between search errors) & $8 \cdot 2(0 \cdot 2) / 12$ & $7 \cdot 5(0 \cdot 2) / 12$ \\
Tower of London test & $(\mathrm{n}=46)$ & Visual memory battery \\
$\quad$ (perfect solutions) & $56 \cdot 7(0 \cdot 5)$ & $(\mathrm{n}=39)$ \\
& $117 \cdot 5(1 \cdot 1)$ & $66 \cdot 1(1 \cdot 0)$ \\
Age (y) & $20 \cdot 9(0 \cdot 4)$ & $114 \cdot 2(1 \cdot 6)$ \\
NART & $16 \cdot 4(0 \cdot 3)$ & $19 \cdot 8(0 \cdot 4)$ \\
Pattern recognition/24 & $4 \cdot 85(0 \cdot 1) / 5$ & $16 \cdot 5(0 \cdot 4)$ \\
Spatial recognition/20 & $4 \cdot 30(0 \cdot 06)$ & $4 \cdot 87(0 \cdot 05)$ \\
Matching to sample: & $4 \cdot 20(0 \cdot 08)$ & $4 \cdot 61(0 \cdot 05)$ \\
Simultaneous & $4 \cdot 20(0 \cdot 20)$ & $4 \cdot 67(0 \cdot 15)$ \\
Delays 0s & $4 \cdot 40(0 \cdot 19)$ & $4 \cdot 26(0 \cdot 15)$ \\
4s & $4 \cdot 70(0 \cdot 17)$ & $4 \cdot 41(0 \cdot 11)$ \\
8s & & $4 \cdot 58(0 \cdot 11)$ \\
16s & $13 \cdot 3(0 \cdot 4)$ & $14 \cdot 2(0 \cdot 4)$ \\
Os (retest) & & \\
Paired associates learning: & & \\
Total trials to criterion & & \\
\hline
\end{tabular}

Table 3 Experimental neuropsychological tests (mean scores (SEM))

\begin{tabular}{|c|c|c|c|}
\hline & $\begin{array}{l}\text { Huntington's } \\
\text { disease }\end{array}$ & $D A T$ & Significance (df) \\
\hline \multicolumn{4}{|l|}{ Sensorimotor screening: } \\
\hline Accuracy (error score) & $43 \cdot 3(6 \cdot 6)$ & $49 \cdot 1(3 \cdot 0)$ & $t(21)=0 \cdot 9, \mathrm{NS}$ \\
\hline Latency (s) & $2 \cdot 24(0 \cdot 39)$ & $1 \cdot 71(0 \cdot 23)$ & $t(21)=1 \cdot 2, \mathrm{NS}$ \\
\hline \multicolumn{4}{|l|}{ Visual memory: } \\
\hline Pattern recognition (/24) & $11.9(1 \cdot 01)$ & $14.5(0.76)$ & $t(21)=2 \cdot 12^{\star}$ \\
\hline Spatial recognition $(/ 20)$ & $10.4(0.56)$ & $12 \cdot 8(0 \cdot 62)$ & $t(21)=2 \cdot 74^{\star \star}$ \\
\hline Spatial span & $2 \cdot 7(0 \cdot 15)$ & $4 \cdot 0(0 \cdot 4)$ & $t(21)=3 \cdot 08^{\star \star}$ \\
\hline \multicolumn{4}{|l|}{ Matching to sample: } \\
\hline \multicolumn{4}{|l|}{ Simultaneous $/ 5$} \\
\hline $\begin{array}{l}\text { Delay/5: } \\
0 \mathrm{~s}\end{array}$ & $3 \cdot 1(0 \cdot 4)$ & $3 \cdot 3(0 \cdot 4)$ & \\
\hline $4 \mathrm{~s}$ & $3 \cdot 3(0.3)$ & $3 \cdot 7(0 \cdot 3)$ & \\
\hline $8 \mathrm{~s}$ & $2 \cdot 5(0 \cdot 1)$ & $2 \cdot 5(0.4)$ & \\
\hline \multirow[t]{3}{*}{$16 \mathrm{~s}$} & $1 \cdot 8(0 \cdot 2)$ & $2 \cdot 5(0 \cdot 4)$ & \\
\hline & & & $\begin{array}{l}\text { Group (HD v DAT) } \\
F(1,21)=0.9\end{array}$ \\
\hline & & & Group $\times$ delay, \\
\hline $0 \mathrm{~s}$ retest & $3 \cdot 0(0 \cdot 3)$ & $3.8(0.3)$ & $t(21)=1.63$ \\
\hline \multicolumn{4}{|c|}{ Paired associates, visuospatial learning: } \\
\hline Total trials to criterion & $46 \cdot 4(4 \cdot 0)$ & $38 \cdot 5(4 \cdot 3)$ & $t(21)=1 \cdot 31$ \\
\hline
\end{tabular}

Figure 1 Mean (SEM) values for between and within search errors on the spatial working memory test for Huntington's disease (HD) and probable dementia of the Alzheimer type $(p D A T)$ groups.

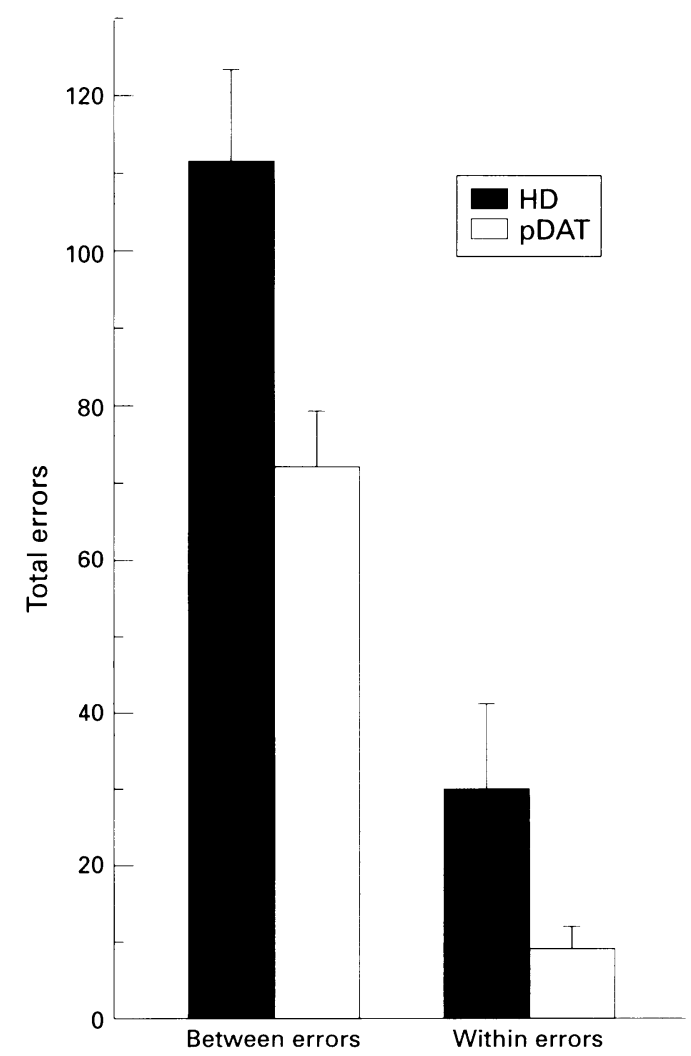

\section{Results}

COMPARISON WITH MATCHED CONTROL GROUPS

For all the measures to be described, both patients with Huntington's disease and those with DAT were significantly worse than their respective control groups of normal volunteers with comparable ages and premorbid estimated IQ (using the national adult reading test (NART); table 2).

SENSORIMOTOR SCREENING TEST

The two groups did not differ significantly on either of the two indices of performance, latency and accuracy of pointing (table 3).

VISUAL MEMORY AND LEARNING (TABLE 3)

The patients with Huntington's disease were significantly worse on both tests of pattern and spatial recognition memory. The patients with Huntington's disease were also worse on simultaneous matching to sample, but the difference disappeared during the delay conditions $(0,4,8,16$ seconds and retest at zero seconds), although, as expected, performance declined significantly over the delays for the two groups overall $(F(3,63)=9 \cdot 84, \quad \mathrm{P}<$ $0 \cdot 001)$. For the paired associates, conditional learning test, the patients with Huntington's disease took more trials to reach criterion for the test as a whole over all stages, but this difference was not statistically significant. In terms of patients reaching criterion at each stage, however, none of the 10 patients with Huntington's disease successfully passed the test when the locations of six patterns had to be remembered, but a significantly higher proportion (five out of 13) of the patients with DAT were successful at this stage $\left(\chi^{2}=6 \cdot 76\right.$, $\mathrm{d} \mathrm{f}=1, \mathrm{P}<0.01)$.

\section{TESTS OF SPATIAL WORKING MEMORY AND PLANNING}

Spatial span

The patients with Huntington's disease had significantly shorter spatial span scores (table 3).

\section{Spatial working memory}

Figure 1 shows that the patients with Huntington's disease committed significantly more between and within search errors in this task $(F(1,21)=10.03, \mathrm{P}<0.005)$. There was also a significant patient group $\times$ set size interaction $(F(3,63)=5.09, \mathrm{P}<0.005)$ as the difference between the groups only emerged after the difficulty level of three boxes.

Tower of London test

The analyses concentrated on three measures of accuracy for the first block of problems. Figure 2 shows that the patients with Huntington's disease were significantly worse in terms of "perfect solutions" at each stage of difficulty (across two, three, and four move problems) (main effect of patient group, $t(21)$ $=3.08, \mathrm{P}<0.001)$. Two other measures of accuracy, total solutions and excess moves, failed to reach significance. Mean (SEM) scores respectively were: HD; $5 \cdot 3(0 \cdot 4)$, $8 \cdot 0(1 \cdot 3)$ : DAT; $4 \cdot 7(0 \cdot 4) ; 6 \cdot 8(1 \cdot 7)$. 
Figure 2 Tower of London planning test. Proportion of problems solved in the minimum number of moves at each stage of difficulty (upper panel) and percentage correct (lower panel). Abbreviations as for fig 1.

Figure 3 Performance in the visual discrimination paradigm. The proportion of patients successfully reaching criterion (6/6) at each stage of the test is shown. $S D=$ simple discrimination stage; SDR $=$ simple discrimination reversal $; C-D=$ compound discrimination with separate elements; $C D=$ compound discrimination; $C D R=$ compound discrimination reversal; IDS = intradimensional shift; $I D R=$

intradimensional reversal; $E D S=$ extradimensional shift, EDR =

extradimensional reversal. Other abbreviations as for fig 1. See Downes et al ${ }^{\circ}$ for further explanation. Note the selective impairment in reversal $(S D R)$ learning in the Huntington's disease (HD) group.
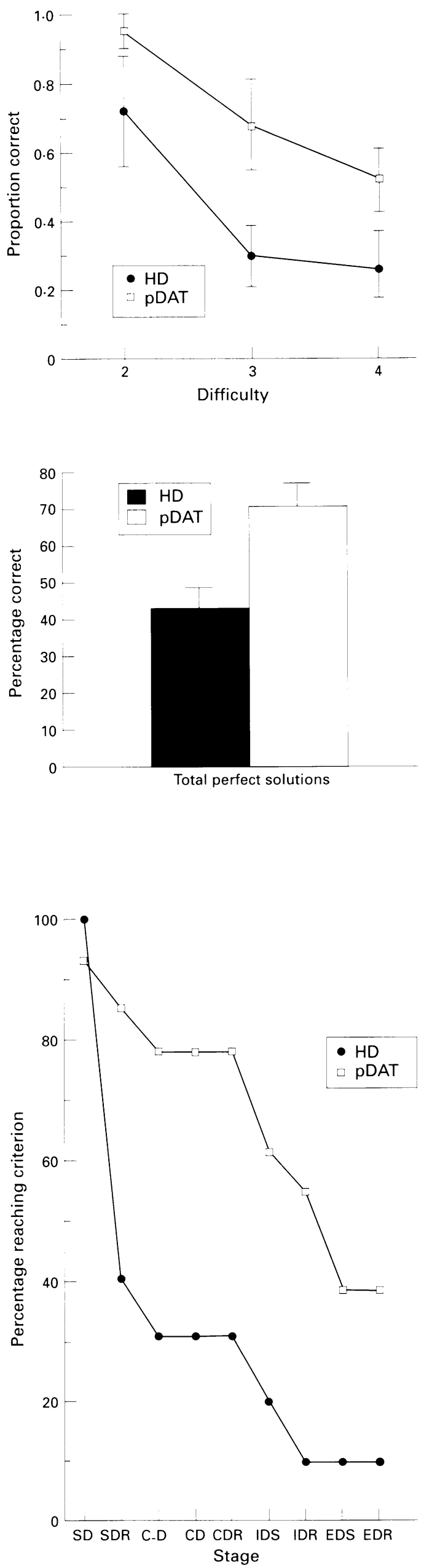

Visual discrimination/attentional set shifting test Figure 3 shows that the patients with Huntington's disease performed significantly worse at the series of visual discriminations. Although the two groups performed equivalently on the test of simple visual discrimination (one out of 13 patients with DAT failed at this stage), as many as six out of 10 of the patients with Huntington's disease failed at the next stage, of simple discrimination reversal, when the previously correct stimulus became incorrect and vice versa. This difference was significantly different $\left(\mathcal{X}^{2}(1)=7 \cdot 17\right.$, $\mathrm{P}<0.01)$. In addition, the nature of the failure of these six patients with Huntington's disease was particularly illuminating because the average number of errors made for the 50 trials was 42.5 (SEM 3.3), indicating a high degree of perseveration of responding towards the initially correct stimulus. The rate of attrition of subjects across the remaining stages of the test was parallel and roughly equivalent. The poor performance of both groups can be seen from our unpublished observations that most (about $70 \%$ ) of 342 elderly normal controls successfully negotiate all parts of the test, most of the failures normally occurring at the extradimensional shift stage. In this large sample, there was no significant difference between the younger $(50-59)$ and older (60-69) control groups (see also Owen et al ${ }^{12}$ for representative data on a smaller sample).

\section{Discussion}

This neuropsychological comparison of DAT and Huntington's disease has shown that, when matched for level of dementia, patients with Huntington's disease are significantly inferior to patients with DAT in three tests of cognitive function (spatial working memory, visual discrimination/attentional set shifting, and the Tower of London planning task) previously shown to be sensitive to frontal lobe damage and basal ganglia dysfunction. The results are thus consistent with hypotheses that the neural substrates of many of the cognitive deficits in Huntington's disease are centred on the caudate nucleus ${ }^{36} 38$ but that additional cortical atrophy may also be significant. ${ }^{37}$

The neural specificity of the three main cognitive tests may be gauged from the fact that the Tower of London task is insensitive to temporal lobe excisions and amygdalohippocampectomy, ${ }^{19}$ as well as more generally to posterior cortical damage. ${ }^{31}$ Performance on the visual discrimination/attentional set shifting paradigm has similarly been shown not to be affected by temporal lobe excisions or amygdalohippocampectomy, ${ }^{14}$ and both of these lesions have much less effect on performance on the spatial working memory task than either frontal lesions ${ }^{11}$ or basal ganglia dysfunction. ${ }^{9}{ }^{17}$ By contrast, certain other tests from the CANTAB battery such as visual pattern recognition or delayed matching to sample are more affected by lesions of the temporal lobe structures than frontostriatal damage. ${ }^{19}$ 
Therefore, the more pronounced executive deficits shown by the patients with Huntington's disease have a degree of neural specificity, consistent with the existence of greater frontostriatal pathology in Huntington's disease than in DAT.

The inferior performance of patients with Huntington's disease was not limited to tests clearly requiring executive function, as they were also significantly impaired relative to patients with DAT in tests of perceptual matching to sample, a visual pattern recognition task, a spatial recognition task, spatial span, and in learning sets of visuospatial paired associates. Performance on a difficult visual delayed matching to sample task was also impaired relative to controls, but not to a greater extent than for patients with DAT. Similar results have been reported for patients late in the course of Parkinson's disease ${ }^{18} 39$ possibly due to additional pathology that may affect functioning in cortical regions other than the prefrontal cortex, such as the temporal lobe. The greater magnitude of these deficits in Huntington's disease than in DAT, however, suggests an alternative (though not mutually incompatible) possibility, that the late cognitive deficits in Parkinson's disease and Huntington's disease reflect pathology of the striatum, most likely the caudate nucleus.

Before comparing these results with others, obvious explanations of the differences should be considered. Although the patients with Huntington's disease and those with DAT differed in age, the greater deficits in the case of the Huntington's disease group cannot be artefacts of relative impairments produced by age related changes in the normal population, as the Huntington's disease group was younger and control performance on these tests usually deteriorates slightly with age. Nor can it be said that the patients with Huntington's disease were globally impaired on all tests. Thus accuracy was apparently equivalent in delayed matching to sample for patients with Huntington's disease and DAT when visual patterns had to be retained over a short delay. The two groups were carefully matched for degree of dementia using Folstein's MMSE, and the patients with DAT performed almost significantly worse than the patients with Huntington's disease on Kendrick's object learning test (taken from the Kendrick cognitive tests for elderly people). An explanation of the results in terms of a greater motor deficit in Huntington's disease somehow interfering with cognitive performance of the touch screen tasks also seems most unlikely. Both accuracy and latency of responding in the sensorimotor screening test, which required the subject to point to selected locations on the screen, were equivalent in the two groups. Furthermore, many of the deficits, such as the gross impairment of simple reversal in the patients with Huntington's disease, have to be set against their relatively successful performance in the simple discrimination phase of the task.

These results are consistent with several examples of double dissociations between
Huntington's disease and DAT in other domains of cognitive function. Patients with Huntington's disease are generally superior to patients with DAT on tests of verbal recognition, ${ }^{40}$ episodic memory, ${ }^{7}$ some aspects of semantic memory, ${ }^{71}$ and implicit (priming) memory, ${ }^{42}$ retrograde amnesia, ${ }^{4344}$ visuoconstructional performance ${ }^{45}$ (though see Hodges et $a l^{7}$ ), but inferior on tests of mental arithmetic, ${ }^{5}$ procedural learning, ${ }^{46}{ }^{47}$ retrieval (such as letter and category fluency ${ }^{78}$ ), and egocentric perception. ${ }^{45}$ Without attempting to account for the whole range of cognitive deficits in Huntington's disease, this pattern of deficits is broadly consistent with the greater involvement of frontostriatal than posterior cortical pathology in this disorder (see also Brandt and Bylsma ${ }^{5}$ ), as the data presented here imply. It was nevertheless interesting to find that the patients with Huntington's disease were more impaired in some of the tests of visual memory and learning such as pattern and spatial recognition, and visuospatial paired associates learning than the patients with DAT, although the reverse was the case for the Kendrick object learning test, which involves the verbal recall of pictures of everyday objects. The relative impairment in pattern and spatial recognition memory in Huntington's disease may seem to contradict earlier results, ${ }^{40}$ but the patients with Huntington's disease and those with DAT were not explicitly matched for degree of dementia in that earlier study. Moreover, the relative impairment in pattern recognition memory in Huntington's disease was not found in the related test of delayed matching to sample. The impairment in simultaneous matching to sample in the Huntington's disease group relative to DAT, supports the finding of visual perceptual impairments underlying naming deficits. ${ }^{49}$ The difference is also reminiscent of other impairments in this test that we have reported in patients with basal ganglia disorders, compared with sparing in mild DAT. ${ }^{18} 39$

The relatively novel feature of the present study is its focus on tests sensitive to executive control over performance and to frontal lobe dysfunction, aspects of cognition in Huntington's disease that have been the subject of only a few investigations..$^{50-52}$ In the introduction, it was pointed out that deficits in tests of executive function may nevertheless differ qualitatively between patients with frontal lobe lesions and basal ganglia disorders such as Parkinson's disease. For example, demented patients with Parkinson's disease have been found to have excessive problems with the Wisconsin card sorting test. ${ }^{8}$ Closer inspection of this result, however, shows that this deficit was restricted to the initial phase, when subjects are striving to attain the first set, rather than to switching sets. In the present study, deficits for patients with Huntington's disease also occurred early in the visual discrimination paradigm that divides the Wisconsin card sorting test into more elementary cognitive components, notably at the simple reversal stage. 
Impairments at this early stage of the test are not necessarily hallmarks of frontal lobe (or executive) dysfunction. In anatomical terms, whereas reversal learning in animals is impaired by damage to the medial orbitofrontal cortex ${ }^{53}$ and the region of the striatum to which it projects, ${ }^{54}$ such deficits are also known to occur-for example, after damage to the amygdala. ${ }^{55} \mathrm{~A}$ more telling piece of evidence was that the performance of patients with Huntington's disease, unlike those with DAT was very perseverative in nature, possibly implicating dysfunction of the orbitofrontal cortex and associated outflow via the caudate nucleus. Jones and Mishkin $^{53}$ found that lesions to the orbitofrontal cortex produced just this form of deficit in monkeys, whereas lesions to the amygdala produced more pervasive deficits in learning new stimulusreward associations. There is evidence that this form of perseveration in reversal learning may be distinct from failures to shift attentional set at the extradimensional shift stage, ${ }^{55}$ which we have found to be a sensitive indicator of cognitive impairment in patients early in the course of Huntington's disease (unpublished findings), as well as in other forms of basal ganglia disease, including Parkinson's disease, Steele-Richardson-Olsewski syndrome, and multiple system atrophy. ${ }^{1617}$ Other forms of perseveration, such as occur in tests of verbal fluency, are not apparently a major feature of Huntington's disease. ${ }^{5}$ The Huntington's disease deficit in visual discrimination reversal learning is of further theoretical interest because it can be viewed as a difficulty in learning new stimulus-response habits, theorised by some authors ${ }^{56}$ to be an expression of the procedural learning that has been postulated to form part of the function of structures within the basal ganglia. It seems, however, that the deficit is not so much one of acquiring new visual habits, as of inhibiting previously acquired ones.

The impairments in spatial working memory were also consistent with a pronounced propensity for perseveration, as the number of between search errors (inappropriately returning to a previously successful choice) was very high, as great numerically as in any other disorder we have examined, including frontal lobe damage. This perseverative tendency was also manifest in terms of repeated, although ineffective, responses within a search sequence (within search errors). Studies with groups of neurosurgical patients with frontal lobe lesions ${ }^{11}$ and other groups with basal ganglia disease $\mathrm{e}^{1617}$ as well as experimental animals in directly analogous tasks ${ }^{55}$ support the view that the pattern of performance on this task most likely reflects dysfunction of frontostriatal circuitry.

It was hardly surprising to find planning performance in Huntington's disease to be severely affected, given that component capacities, such as spatial span and spatial working memory were themselves so severely impaired. The deficit in planning was manifest even on the easy problems (for example, "two movers"), although extensive practice with one and two move problems ensured that the Huntington's disease and DAT groups understood the requirements of the task. Impairment at such an early stage, however, suggests that it is not truly a planning dysfunction as such, but represents a failure of perceptual schemas (standard arrangements of the set of three balls leading to routine choices) accurately to elicit the correct combination of moves. This requires further investigation, because it is reminiscent of a failure in contention scheduling among sensory cued response options described by Shallice ${ }^{31}$ rather than a loss of supervisory function, equivalent to executive control. In neural terms these two mechanisms have been linked respectively to basal ganglia ${ }^{57}$ and frontal lobe function $^{31}$ and so the Huntington's disease deficit is probably consistent with its well established striatal (especially caudate) pathology. In general, such differences in the precise pattern of deficits in the tests of executive function between patients with Huntington's disease and those with frontal lobe damage are consistent with the secondary hypothesis outlined in the introduction that the precise nature of the deficits in these patient groups may depend on the distinct ways in which normal functioning of the corticostriatal loops is disrupted.

Overall, it is apparent that the cognitive deficits in the later stages of Huntington's disease can be every bit as wide ranging as in moderate DAT, including not only executive functions, but also fundamental forms of processing that further undermine the operation of executive processes. Even at this later stage, however, it is clear that there exist qualitative differences in cognitive function between these conditions. Presumably, these differences would be accentuated in the earliest stages of both diseases, and the future focus of work on Huntington's disease should perhaps concentrate on its early stages, and on patients at risk for the disease. Using the same battery of tests described here in a series of cross sectional comparisons of patients with Parkinson's disease at various stages, we have reported $^{912}$ that the tests employed here that are sensitive to frontal lobe dysfunction are the most sensitive to early Parkinson's disease, whereas later stages of the disease are associated with significant declines in visual memory and learning ${ }^{39}$ that may be related to the progressive neuropathological changes occurring in Parkinson's disease. It is to be hoped that a similar cross sectional or alternatively, longitudinal, study of Huntington's disease would help to relate different aspects of the cognitive impairments associated with the disease to discrete components of the underlying neuropathology.

This work was supported by a programme grant from the Wellcome Trust. We thank Professor R Levy for referrals of patients with DAT, Professor P Rabbitt for providing control subjects, and Merle James, Andrew Lawrence, and Dr Adrian Owen for their assistance. We are also grateful to the residents and staff of the Sue Ryder Home, Stagenhoe Park, Hertfordshire, for their kind support of this study. KWL was supported by the Deutsche Forschungsgemeineschaft. 
1 Albert M, Feldman RG, Willis AL. The "subcortical dementia" of progressive supranuclear palsy. $f$ Neurol Neurosurg Psychiatry 1974;37:121-30.

2 Cummings JL, Benson DF. Subcortical dementia: neuropsychology, neuropsychiatry and pathophysiology. Arch Neurol 1984;41:874-9.

3 Alexander GE, DeLong MR, Strick PL. Parallel organization of functionally segregated circuits linking basal ganglia and cortex. Annu Rev Neurosci 1986;9:357-81.

4 Bamford KA, Caine ED, Kido DK, Plassche WM Shoulson I. Clinical-pathological correlation in Huntington's disease: a neuropsychological and computed tomography study. Neurology 1989;39:796-801.

5 Brandt JA, Bylsma FW. The dementia of Huntington's disease. In: Parks RW, Zec RF, Wilson RS, eds. Neuropsychology of Alzheimer's disease and other dementia. New York: Oxford University Press, 1993:265-82.

6 Brown RG, Marsden CD. "Subcortical dementia": the neuropsychological evidence. Neuroscience 1988;25: 363-387.

7 Hodges JR, Salmon DP, Butters N. Differential impairment of semantic and episodic memory in Alzheimer's and Huntington's diseases: a controlled prospective study. F Neurol Neurosurg Psychiatry 1990;53:1089-95.

8 Litvan I, Mohr E, Williams J, Gomez C, Chase TN. Differential memory and executive functions in demented patients with Parkinson's and Alzheimer's disease. $\mathcal{F}$ Neurol Neurosurg Psychiatry 1991;54:25-9.

9 Downes JJ, Roberts AC, Sahakian BJ, Evenden JL, Morris RG, Robbins TW. Impaired extra-dimensional shift performance in medicated and unmedicated Parkinson's disease: evidence for a specific attentional dysfunction. disease: evidence for a specific atte

10 Sahakian BJ, Downes J, Eagger S, et al. Sparing of atten tional relative to mnemonic function in a subgroup of tional relative to mnemonic function in a subgroup of patients with dementia of the

11 Owen AM, Roberts AC, Polkey CE, Sahakian BJ, Robbins TW. Extradimensional versus intradimensional set shifting performance following frontal lobe excisions, temporal lobe excisions or amygdala-hippocampectomy in man. Neuropsychologia 1991;29:993-1006.

12 Owen AM, James M, Leigh PN, et al. Fronto-striatal cognitive deficits at different stages of Parkinson's disease. Brain 1992;115:1727-51.

13 Parks RW, Haxby JF, Grady CL. Positron emission tomography in Alzheimer's disease. In: Parks RW, Zec RF, Wilson RS, eds. Neuropsychology of Alzheimer's disease and other dementia

14 Sahgal A, Lloyd S, Wray CJ, et al. Does visuospatial memory in Alzheimer's disease depend on the severity of the disorder? International fournal of Geriatric Psychiatry disorder? Internat

15 Owen AM, Downes J, Sahakian BJ, Polkey CE, Robbins TW. Planning and spatial working memory following
frontal lobe lesions in man. Neuropsychologia 1990;28: frontal lo 1021 .

16 Robbins TW, James M, Lange KW, Owen AM, Quinn NP, Marsden CD. Cognitive performance in multiple system atrophy. Brain 1992;115:271-91.

17 Robbins TW, James M, Owen AM, et al. Cognitive deficits in progressive supranuclear palsy, Parkinson's diseas and multiple system atrophy in tests sensitive to frontal lobe dysfunction. F Neurol Neurosurg Psychiatry 1994;57: 79-88.

18 Sahakian BJ, Morris RG, Evenden JL, et al. A comparative study of visuospatial memory and learning in Alzheimer type dementia and Parkinson's disease. Brain 1988;111: 695-718.

19 Owen AM, Sahakian BJ, Semple J, Polkey CE, Robbins TW. Visuospatial short term recognition memory and learning after temporal lobe excisions, frontal lobe excisions or amygdala-hippocampectomy in man Neuropsychologia 1995;33:1-24.

20 Folstein MF, Folstein SE, McHugh PR. Minimental state.

f Psychiatr Res 1975;12:189-98.
21 Kendrick DC. Kendrick cognitive tests for the elderly. Windsor: NFER Nelson, 1985.

22 Nelson HE. National adult reading test manual. Windsor: NFER Nelson, 1982

23 Robbins TW, James M, Owen AM, Sahakian BJ, McInnes L, Rabbitt P. Cambridge neuropsychological test automated battery (CANTAB): a factor analytic study of a large sample of normal elderly volunteers. Dementia 1994;5:266-81.

24 Philpot MP, Levy R. A memory clinic for the early diagnosis of dementia of the Alzheimer type. International fournal of Geriatric Psychiatry 1987;2:195-200.

25 McKhann G, Drachman D, Folstein M, Katzman R, Price D, Stadlin EM. Clinical diagnosis of Alzheimer's disease: report of the NINCDS-ADRDA work group under the auspices of the Department of Health and Human
Services Task Force on Alzheimer's disease. Neurology 1985;34:939-44.

26 Hughes CP, Berg L, Danziger WL, Coben LA, Martin RL. A new clinical scale for the staging of dementia. $\mathrm{Br} f$ Psychiatry 1982;140:566-72.

27 Eagger SA, Levy R, Sahakian BJ. Tacrine in Alzheimer's disease. Lancet 1992;337:989-92.

28 David AS, Jeste DV, Folstein MF, Folstein SE. Voluntary movement dysfunction in Huntington's disease and tardive dyskinesia. Acta Neurologica Scandinavica 1987; 75:130-9.
29 Sahakian BJ, Owen AM. Computerised assessment in neuropsychiatry using CANTAB. f $R$ Soc Med 1992;85: 399-402.

30 Milner B. Interhemispheric differences in the localization of psychological processes in man. Br Med Bull 1971; 27:272-7.

31 Shallice $T$. Specific impairments in planning. In Broadbent DE, Weiskrantz L, eds. The neuropsychology of cognitive function. London: The Royal Society, 1982: 199-209.

32 Roberts AC, Robbins TW, Everitt BJ. The effects of intradimensional and extradimensional shifts on visual discrimination in humans and non-human primates. $Q \mathcal{F}$ Exp Psychol 1988;40B:321-41.

33 Winer BJ. Statistical principles in experimental design. 2nd ed New York: McGraw-Hill, 1971.

34 Kullback S. Information theory and statistics. New York: Dover, 1968.

35 Robbins TW. A critique of the methods available for the measurement of spontaneous locomotor activity. In: Iversen LL, Iversen SD, eds. Handbook of psychopharm cology. Vol 7. New York: Plenum Press, 1977;37-82.

36 Starkstein SE, Brandt J, Bylsma F, Peyser C, Folstein M Folstein SE. Neuropsychological correlates of brain atrophy in Huntington's disease: a magnetic

37 Berent S, Giordani B, Lehtinen S, et al. Positron emission tomographic scan investigations of Huntington's disease: cerebral metabolic correlates of cognitive function. Ann Neurol 1988;23:541-6.

38 Weinberger DR, Beran KE, Iadrola, Driesen N, Zec R. Prefrontal cortical blood flow and cognitive function in Huntington's disease. $₹$ Neurol Neurosurg Psychiatry 1988;51:94-104.

39 Owen AM, Bekinska $M$, James $M$, et al. Visuospatial memory deficits at different stages of Parkinson's disease. Neuropsychologia 1993;31:627-44.

40 Moss M, Albert MS, Butters N, Payne M. Differential patterns of memory loss among patients with Alzheimer's disease, Huntington's disease and alcoholic Korsakoff syndrome. Arch Neurol 1986;43:239-46.

41 Troster AI, Salmon DP, McCullogh D, Butters N. A comparison of category fluency effects associated with Alzheimer's and Huntington's disease. Brain Lang 1989 37:500-13.

42 Bylsma FW, Rebok GW, Brandt J. Long-term retention of implicit learning in Huntington's disease. Neuropsychologia 1991;29:1213-21.

43 Beatty WW. Remote memory for visuospatial information in patients with Huntington's disease. Psychobiology 1980;17:431-4.

44 Beatty WW, Goodkin DE, Monson N, Beatty PA Hertsgaard D. Retrograde amnesia in patients with Alzheimer's disease or Huntington's disease. Neurobiol Aging 1988;9:181-6.

45 Brouwers P, Cox C, Martin A, Chase T, Fedio P. Differential perceptual-spatial impairment in Huntington's and

46 Heindel WC, Salmon DP, Shults CW, Walicke PA Butters N. Neuropsychological evidence for multiple implicit memory systems: a comparison of Alzheimer's Huntington's and Parkinson's disease patients f Neurosci 1989;9:582-7.

47 Knopman D, Nissen MJ. Procedural learning is impaired in Huntington's disease; evidence from the serial reaction time task. Neuropsychologia 1991;29:245-54.

48 Butters N, Wolfe J, Granholm E, Martone M. An assessment of verbal recall, recognition and procedural memory. Cortex 1986;22:11-32.

49 Hodges JR, Salmon DP, Butters N. The nature of the naming deficit in Alzheim

50 Rothlind JC Brandt J. A subcortical functions in dementia. $\mathcal{F}$ Neuropsychiatry Clin Neurosc 1993;5:73-7.

51 Pillon B, Dubois B, Ploska A, Agid Y. Severity and specificity of cognitive impairment in Alzheimer's, ficity of cognitive impairment in Alzheimer's, 36:1179-85.

52 Fedio P, Cox CS, Neophytides A, Canal-Frederick G, Chase TN. Neuropsychological profile of Huntington's disease patients and those at risk. In: Chase TN, Wexle NS, Barbeau A, eds. Advances in Neurology. Vol 23, New York: Raven Press, 1979;239-55.

53 Jones B, Mishkin M. Limbic lesions and the problem of stimulus-reinforcement associations. Expt Neurol 1972 36:362-77.

54 Divac I, Rosvold HE, Szwarcbart MK. Behavioral effects of selective ablation of the caudate nucleus. Fournal of Comparative Physiology and Psychiatry 1967;63:184-90.

55 Roberts AC, De Salvia MA, Wilkinson LS, et al. 6-hydroxydopamine lesions of the prefrontal cortex in monkeys enhance performance on an analogue of the Wisconsin Card Sorting test: Possible interactions with subcortical dopamine. F Neurosc 1994;14:2531-44.

56 Mishkin M, Malamut B, Bachavalier J. Memories and habits: Two neural systems. In: Lynch G, McGaugh JL, Weinberger NM, eds. Neurobiology of learming and mem ory. New York: Guildford Press, 1984:65-77.

57 Robbins TW, Sahakian BJ. The neuropsychological significance of the behavioural effects of psychomotor stimuicance In Raven Press, 1983:301-38. 